\title{
AVALIAÇÃO DAS CONSEQUÊNCIAS DO GALGAMENTO COSTEIRO DE 10/11 DE DEZEMBRO DE 2013 NA FRENTE URBANA DO CONCE- LHO DE SANTA CRUZ, ILHA DA MADEIRA
}

\author{
CONSEQUENCES EVALUATION OF THE OVERTOPPING EPISODE OF THE 10/11 DE- \\ CEMBER 2013 ON THE URBAN FRONT OF SANTA CRUZ MUNICIPALITY, MADEIRA IS- \\ $L A N D$
}

\author{
ANA PEIXOTO ${ }^{(1)} \&$ ALBERTO GOMES $^{(2)}$
}

Resumo:

Abstract:

\section{INTRODUÇÃ̃O}

O litoral constitui uma área muito suscetível aos perigos naturais, particularmente em frentes costeiras muito urbanizadas onde se reúnam condições hidrogeomorfológicas específicas que favorecem a ocorrência de galgamentos costeiros durante eventos extremos de agitação marítima.

$\mathrm{O}$ galgamento das infraestruturas e equipamentos implantados no litoral, em norma, designado como galgamento costeiro ou marítimo, corresponde à transposição de uma estrutura marí-

\begin{abstract}
A expansão e consolidação de áreas urbanas no litoral conduzem à exposição de um elevado número de elementos antropicos no decorrer de galgamentos costeiros. É com o intuito de identificar e classificar as consequências de galgamentos costeiros que analisamos o recente storm surge de 10/11 de dezembro de 2013 que afetou a faixa costeira urbana da cidade de Santa Cruz, na costa sul da Ilha da Madeira. Assim, enquadra-se as condições atmosféricas relativas à intensidade do vento e à pressão atmosférica durante evento e caracteriza-se a agitação maritima através da direção e altura máxima da ondulação, bem como, a variação da maré. Após a caracterização difícios, estruturas de proteção costeira e equipamentos, bem como, as consequências nas funções dos equipamentos portuários afetados pelo galgamento. Da análise quantitativa dos dados oceanográficos e atmosféricos, concluiu-se que o galgamento é do tipo green water, resultante de uma tempestade extratropical acompanhada de um rápido da pressão atmosférica e de uma velocidade média dos ventos de $30 \mathrm{~km} / \mathrm{h}$. O galgamento costeiro afeto de forma mais danosa cerca de 1600 metros do litoral de Santa Cruz. A análise qualitativa das consequências, revela mais afetadas localizam-se nos extremos da frente urbana da cidade, registando-se consequências reduzidas a insignificantes na área intermédia. Deste modo, aponta-se como áreas de maior exposição, as áreas que registaram danos sérios a muito sérios, os quais, se poderão acentuar em futuros eventos.
\end{abstract}

Palavras-chave: galgamento costeiro, elementos expostos, Ilha da Madeira

Keywords: overtopping, exposed elements, Madeira Island

Received: 14 January, 2021 ; Accepted: 30 November, 2021

tima por uma massa de água por ação da agitação marítima (Usace, 1995, Pullen et al, 2007, Patricio, 2012), i.e., quando a onda transpõe a cota de coroamento das estruturas litorais, causando inundações, arrastamento de pessoas e/ou danos estruturais e funcionais (Brito, 2007; Rodrigues, 2011; SiLVA et al., 2012). A rebentação das ondas sobre a estrutura e a consequente transposição, normalmente, advém de um cenário de tempestade marítima (ВRITo, 2007; Haslet \& BRyan, 2009; Rodrigues, 2011) ou decorrente

\footnotetext{
(1) Câmara Municipal do Funchal, Portugal. Autor correspondente: isapilotolgeogr@gmail.com (Ana Peixoto);

(2) CEGOT - Centro de Estudos de Geografia e Ordenamento do Território, Faculdade de Letras da Universidade do Porto, Portugal
} 
de um tsunami (HSIAO \& Lin, 2010; Lynett et al., 2003). Num sentido mais genérico, a NOAA (National Oceanic and Atmospheric Administration) indica que as tempestades (ventos fortes, chuvas torrenciais e baixas pressões) são uma das causas das inundações costeiras que submergem as áreas litorais de baixa altitude.

Para além da suscetibilidade natural, associa-se às áreas litorais uma importante componente de vulnerabilidade do território, uma vez que inúmeras áreas urbanas se implantam na frente costeira, concentrando um elevado número de elementos expostos (Dwyer et al. 2004). Com a expansão da urbanização ao longo de frentes costeiras (ANCP, 2010; RochA et al., 2012), as áreas litorais tornaram-se mais vulneráveis à provável elevação do nível do mar (IPCC, 2013) e aos efeitos dos eventos naturais extremos ligados a tempestades, a ventos ciclónicos e episódios de precipitação intensa (KRON, 2013).

A frente costeira da cidade de Santa Cruz localizada na costa sul da Ilha da Madeira, constitui um exemplo do território português onde a perigosidade a galgamentos costeiros é real. Para além disso, este território, à semelhança do que acontece na costa sul da ilha, constitui uma importante área económica e urbana (Rusu et al., 2008), registando uma forte densidade populacional 555,6 hab/ $\mathrm{km}^{2}$ (INE, 2012) e uma forte concentração de edificado residencial, turístico e de equipamentos (Torres \& ANDrade, 2010). Na área de estudo delimitada pela Ribeira da Boaventura e pelo Porto de Recreio, sensivelmente, uma área costeira abaixo dos 5 metros de altitude, identificam-se como principais elementos expostos duas infraestruturas portuárias, as piscinas municipais e alguns estabelecimentos comerciais e hoteleiros (Figura 1), o que se traduz em danos estruturais e na interrupção do funcionamento normal da cidade quando ocorrem galgamentos costeiros (Рexхто, 2013)

No Inverno de 2013, ocorreu um episódio de forte agitação marítima que afetou o litoral de Santa Cruz durante os dias 10 e 11 de dezembro, facto que suscitou o interesse para uma análise do perigo a galgamentos costeiros neste sector. Assim, o objetivo deste trabalho é duplo. Por um lado, enquadrar as condições atmosféricas e de agitação marítima que desencadearam o episódio de 10 de dezembro, e identificar as consequências e processos que sucederam durante este evento, de forma a identificar as áreas mais suscetíveis a galgamentos costeiros.
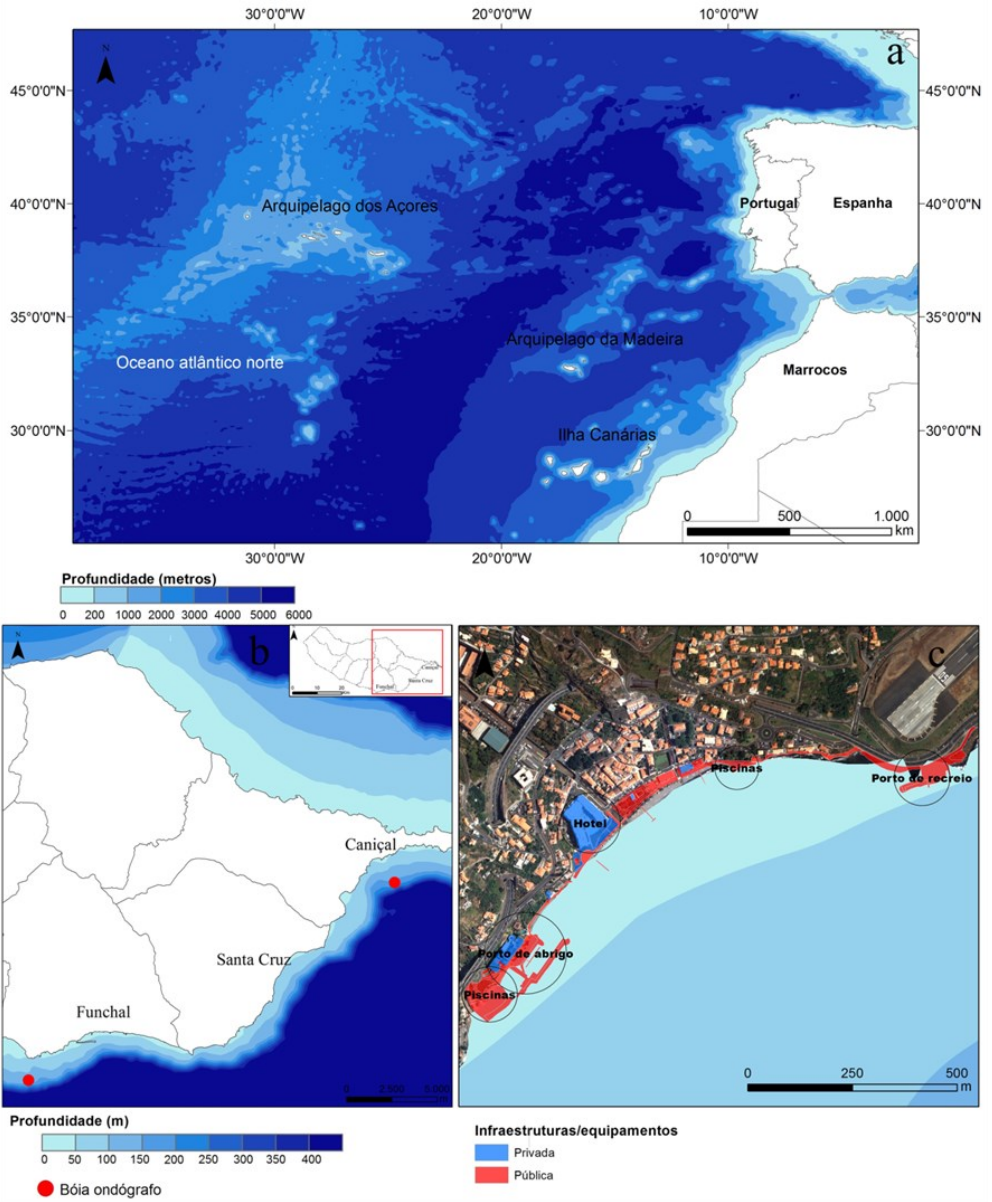

Fig. 1. Enquadramento geográfico da Ilha da Madeira: a - Ilha no oceano atlântico norte; b- Batimetria do setor oriental da Ilha da Madeira; c - Faixa costeira da cidade de Santa Cruz. Os dados batimétricos usados nos mapas podem ser obtidos em http:// www.hidrografico.pt/download-gratuito.php

Fig. 1. Geographic setting of Madeira Island: a - Island in the North Atlantic Ocean; b- Bathymetry of the eastern sector of Madeira Island; c - Coastal strip of Santa Cruz city. The bathymetric data used in the maps can be obtained from http://www.hidrografico.pt/downloadgratuito.php. 


\subsection{A Costa Sul da Madeira}

A Ilha da Madeira, região portuguesa e ultraperiférica da União Europeia (Rusu et al., 2012), localiza-se no atlântico norte (Figura 1) e possuiu uma costa rochosa, composta por arribas de grande altitude (Fernandes, 2009, Neves, 2010), como é exemplo a arriba com $c a$. $600 \mathrm{~m}$ de altura no $\mathrm{Ca}$ bo Girão, contrastando com algumas baías da costa sul. A erosão marinha destas arribas originou algumas áreas da orla costeira de menor altitude (Fernandes, 2009), que na atualidade são constituídas por praias de calhaus rolados (NEves, 2010), com granulometrias variáveis (SILVEIRA et al., 2010).

Em termos de maré, o porto do Funchal regista uma maré semidiurna, seguindo um regime mesomareal em que que a amplitude máxima anual atinge os 2,8 metros (IH, 2013).

No que se refere ao ambiente batimétrico a ilha é marcada pelos fortes gradientes, atingindo- se os 4000 metros de profundidade na proximidade da plataforma insular (CIIMAR-MADEIRA, 2013). Esta rápida mudança de profundidade é particularmente sensível na costa sul (Rusu et al., 2008; CAMPUZANo et al., 2004). Face a este forte gradiente batimétrico, infere-se que a rebentação das ondas deve ocorrer muito próximo da linha de costa.

A costa sul devido a sua posição geográfica encontra-se "protegida dos processos de refraçãodifração combinados" (Rusu et al., 2008), uma vez que, não é influenciada pela ondulação vinda de noroeste e norte (Esteves \& PINTO, 2007), nem pelos ventos dominantes, o que coloca-a desprotegida das tempestades com direção sudeste e sudoeste (ToRres \& ANDRADE, 2010).

Em média, a ondulação na costa sul possuí uma direção oeste ou sul atingindo altura significativa entre 0,5 a 1 metro (Quadro 1), dependendo da posição geográfica da área em análise, estação do Funchal ou do Caniçal.

Tab. 1. Caracterização da agitação marítima da estação ondógrafo do Funchal e do Caniçal (adaptado de EsTEVES \& PINTO, 2007) Tab.1. Characterization of wave propagation at Funchal and Caniçal wave stations (adapted from EsTEvES \& PINTO, 2007)

\begin{tabular}{|c|c|c|c|c|c|c|c|c|}
\hline Estação & \multicolumn{4}{|c|}{ Funchal } & \multicolumn{4}{|c|}{ Caniçal } \\
\hline & Direcã ** & Altura significativa & Altura & áxima & Direcão* & Altura significativa & Altura & xima \\
\hline & & $(m)^{*}$ & $(m)^{*}$ & $(m) *$ & & $(m)^{*}$ & $(m)^{*}$ & $(m)^{* *}$ \\
\hline $\begin{array}{l}\text { Anual } \\
\text { Anuço }\end{array}$ & w & $0,5-1$ & & 12 & S & 0,5 & & 7 \\
\hline $\begin{array}{l}\text { Ondulação predominante: } \\
\text { Inverno }\end{array}$ & W & $0,55-1,18$ & $>3$ & & SE & $<1$ & $2-4$ & \\
\hline Verão & $\begin{array}{l}S \\
E\end{array}$ & $<1$ & $<3$ & & $\begin{array}{l}\mathrm{s} \\
\mathrm{W}\end{array}$ & $<1$ & $1-2,3$ & \\
\hline
\end{tabular}

** Dados referentes aos registos da ondulaçöo por bóia ondógrafo no periodo compreendido entre 1999 e 2013 (Instituto Hidrogrifico)

Tab. 2. Ocorrência de cenários de tempestade na estação ondógrafo do Funchal (adaptado de EsTEVES \& PINTO , 2007) Tab. 2. Occurrence of storm scenarios at Funchal wave station (adapted from ESTEVES \& PINTO , 2007)

\begin{tabular}{|c|c|c|c|c|c|c|c|c|c|c|}
\hline \multicolumn{11}{|c|}{ Estação do Funchal } \\
\hline \multicolumn{6}{|c|}{ Direção } & \multirow{2}{*}{$\begin{array}{c}\text { Altura } \\
\text { Máxima }\end{array}$} & \multicolumn{4}{|c|}{ Duração (dias) } \\
\hline $\mathrm{SE}$ & SSE & SSW & SW & WSW & $\mathrm{W}$ & & $<1$ & $1-2$ & $>2$ & Total \\
\hline \multirow[t]{4}{*}{$\mathrm{X}$} & $\mathrm{X}$ & $\mathrm{X}$ & $\mathrm{X}$ & $\mathrm{X}$ & $\mathrm{X}$ & $3-4$ & 26 & 4 & 0 & 30 \\
\hline & & & $\mathrm{X}$ & $\mathrm{X}$ & $\mathrm{X}$ & $4-5$ & 7 & 9 & 5 & 21 \\
\hline & & & & $\mathrm{X}$ & & $>5$ & 0 & 0 & 1 & 1 \\
\hline & & & & & & & 33 & 13 & 6 & 52 \\
\hline
\end{tabular}

Dados médios referentes à observação da ondulação no periodo compreendido entre 1989 e 2006 (ESTEVES \& PINTO, 2007)

Os dados referentes à ondulação observado no período de 1989 a 2006 e disponibilizados pelo Instituto Hidrográfico, demonstram que a estação do Funchal possui, em média, uma ondulação nos meses de inverno de oeste com uma altura significativa entre os 0,55 metros a 1,18 metros. Já no que se refere aos cenários de tempestade, apesar da sua pouca expressividade, na estação do Funchal observa-se uma ondulação de 3 a 4 metros com predominância da direção de oeste e oeste-sudoeste
(Quadro 2). Os dados mais recentes da bóia ondógrafo estacionada frente ao Funchal evidenciam um valor de altura máxima de 12 metros. No que se refere, à duração das tempestades a regra é a de que não excedem um dia, contudo, quando se prolongam são acompanhadas por um aumento da altura da ondulação. É exemplo o temporal analisado (2 dias) em que a ondulação superou os 5 metros. Outro padrão na duração das tempestades corresponde às ocorrências das tempestades com a 
direção de sudeste que se manifestam num período inferior a 6 horas (Esteves \& Pinto, 2007). Apesar de raras, verificaram-se episódios de agitação marítima sem uma direção dominante (Esteves \& Pinto, 2007), com variações superiores a $90^{\circ}$. Estas situações são explicadas por rápidas mudanças da circulação atmosférica.

$\mathrm{Na}$ estação do Caniçal, em comparação com a estação do Funchal, a ondulação possui pouca expressividade, uma vez que, a altura significativa ao longo do ano não ultrapassa 1 metro (Quadro 1), em parte, por estar protegida das influências de oeste Esteves \& Pinto, 2007). Por conseguinte, assume-se, que a estação do Funchal é a que se aproxima mais do regime de agitação marítima registada na área da cidade de Santa Cruz.

Em termos atmosféricos existem duas influências sazonais a considerar: o anticiclone dos Açores e o do Marrocos. O primeiro, exerce a sua ação nos meses de inverno quando se encontra a sul, tornando a energia das ondas mais intensa (Rusu et $a l ., 2008$ ). Tal é explicado pela formação de ventos alísios de nordeste que apresentam rajadas de 20km/h (IH, 1979 citado por CAMPUZANo et al., 2004). Já o anticiclone de Marrocos influencia a ilha no período de novembro a fevereiro com a formação de ventos fortes (Rusu et al., 2008).

\subsection{Elementos expostos na faixa costeira da cidade de Santa Cruz}

A cidade de Santa Cruz (Figura 1c), com uma frente costeira aproximadamente de 1600 metros desde a foz da Ribeira da Boaventura ao Porto de Recreio, é constituída em quase toda extensão por praias de calhaus rolados que assentam sobre areias grosseiras. A faixa terrestre adjacente à praia é composta por inúmeros elementos construídos que podem sofrer danos com a ocorrência de galgamentos costeiros. Nesta faixa costeira existe uma primeira linha de infraestruturas compostas por vários pontões e dois portos (Figura 3), um de abrigo no quadrante oeste e outro de recreio no quadrante leste, seguindo-se numa segunda linha (adjacente às praias), uma promenade com uma extensão igual ao comprimento da baía. Por fim, um pouco mais recuada mas potencialmente exposta, localiza-se a edificação urbana, com a função centrada no setor terciário, como é exemplo, a unidade hoteleira, a restauração e o comércio de retalho.

O crescimento urbano que decorreu no final do século XX originou novas áreas de vulnerabilidade (Регхото, 2013), uma vez que se intensificaram as construções no litoral, que outrora era apenas ocupado por fortes, pelas praias e sedimentos dos leques aluviais terminais das ribeiras.

A evolução da edificação na faixa litoral manifestou-se nos anos 50 e 60, intensificando-se nos anos 90 (séc. XX) com a construção das piscinas municipais e o aumento da promenade. Ainda nesta década foi construído o Porto de Recreio em Santa Catarina, posteriormente melhorado e dotado de acessos. Já no século XXI, no leito de cheia da Ribeira de Santa Cruz edificou-se uma unidade hoteleira e aumentou-se a promenade existente. $\mathrm{Na}$ área da Ribeira de Boaventura, a área abandonada a oriente da ribeira foi reabilitada com uma frente marítima que passou a dispor de jardins, comércio e outros equipamentos. O Porto de Recreio e o Porto de Abrigo servem para a amarração de embarcações de pequeno e média dimensão, destinando-se à atividade piscatória e ao lazer.

Assim, os mais significativos elementos expostos a galgamentos costeiros são: a promenade, os estabelecimentos comerciais, a área de lazer e as infraestruturas costeiras (marinas, piscinas municipais) Por tudo isto, decidiu-se concentrar a nossa análise na faixa litoral delimitada pelo sítio de Santa Catarina (Porto de Recreio) e pela Ribeira da Boaventura.

\section{METODOLOGIA}

A análise do evento de galgamento costeiro na cidade de Santa Cruz decorreu segundo três etapas principais: i) inventário das ocorrências de galgamentos costeiros na cidade de Santa Cruz; ii) recolha e análise dos dados meteorológicos e oceanográficos; iii) identificação e avaliação das consequências do galgamento de 10/11-12-2013.

Em primeiro lugar, identificou-se mediante o trabalho de campo e através de vários registos, as ocorrências que compuseram a cronologia de galgamentos costeiros danosos no período de 1993 a 2010 (Регхото, 2013), ao que se acrescentou as ocorrências recentes. O registo das novas ocorrências adveio do registo fotográfico dos cidadãos e dos meios de comunicação, Jornal da Madeira e Diário de Notícias da Madeira. Assim, no final desta etapa foi possível ter uma ideia preliminar da susceptibilidade desta faixa costeira, bem como a identificação dos elementos expostos na frente urbana da cidade de Santa Cruz.

$\mathrm{Na}$ segunda etapa, seguindo uma abordagem quantitativa, foram analisados os dados da bóia ondógrafo do Funchal por se localizar a cerca de $16 \mathrm{~km}$ da área costeira de Santa Cruz, e porque a bóia ondógrafo do Caniçal está protegida das influências de oeste, não exemplificando as condições que ocorreram no litoral de Santa Cruz. Os dados observados foram a altura e direção da ondulação no período de 22 de novembro a 22 de dezembro de 2013 (dados obtidos no portal do Instituto Hidrográfico). De modo a completar a informação de Esteves \& PINTO(2007) introduziu-se na análise da caraterização da altura máxima das ondas o período de 1993 a 2013.

De forma a correlacionar os dados oceanográficos com as condições meteorológicas, recorreu-se aos dados da estação meteorológica do Funchal, considerando-se como variáveis de análise a intensidade do vento e a pressão atmosférica, no período de 01 de dezembro a 14 de dezembro 2013 e os dados disponíveis para os dias 10 e 11 de dezembro de 2013, no Instituto Português do Mar e da Atmosfera (IPMA). No final desta fase, correlacionou-se a propagação das ondas com a situação atmosférica de forma a tipificar, segundo a classificação de Demirbilek \& Vicent (2002), o sistema de vento responsável pela tempestade marítima de 
10/11 de dezembro.

A terceira etapa dedica-se ao registo dos processos decorridos durante o evento, bem como, das consequências. A avaliação das consequências teve como base os relatos dos meios de comunicação, Jornal de Notícias da Madeira e Diário de Notícias da Madeira (de 10 de dezembro a 12 de dezembro de 2013), bem como a análise de dois vídeos disponíveis sobre o evento. A compilação e o cruzamento da informação, permitiu enquadrar a sucessão de acontecimentos das $00.00 \mathrm{~h}$ do dia 10 de dezembro até às 13:00h do dia 11 de dezembro de 2013. Para assinalar as consequências relatadas, efectuou-se uma visita pela área afetada a 26 de dezembro de 2013 (15 dias após o evento), fotogra- fando-se e registando as consequências que não constavam nos relatos dos meios de comunicação, bem como, inquirindo moradores e instituições locais sobre o episódio.

Após a identificação dos danos na faixa litoral da cidade, avaliou-se os mesmos através do grau de consequência seguindo de perto os critérios definidos no trabalho de Rocha et al. (2012), focando-se na questão funcional da gestão portuária e nos danos estruturais no património, nomeadamente, nos edifícios, equipamentos e estruturas de protecção costeira (Quadro 3). Acrescentou-se aos critérios definidos, a deposição de material nas praias e nas áreas de acesso.

Tab. 3. Classificação do grau de consequências presentes na ocorrência de um perigo (adaptado de RocHA et al., 2012). Tab. 3. Grading degree of consequences in the occurrence of an hazard (adapted from RocHA et al., 2012).

\begin{tabular}{|c|c|c|c|c|}
\hline \multirow{3}{*}{ Descrição } & \multicolumn{4}{|c|}{ Consequências } \\
\hline & \multirow{2}{*}{ Gestão Portuária } & \multicolumn{3}{|c|}{ Património } \\
\hline & & Edificios & Equipamento & Estrutura \\
\hline Insignificantes & $\begin{array}{l}\text { Alterações ligeiras nas } \\
\text { atividades portuárias }\end{array}$ & $\begin{array}{l}\text { Danos } \\
\text { exteriores quase } \\
\text { inexistentes }\end{array}$ & $\begin{array}{l}\text { Danos quase } \\
\text { inexistentes e } \\
\text { deposição de } \\
\text { material }\end{array}$ & $\begin{array}{c}\text { Dano na zona ativa da } \\
\text { estrutura não } \\
\text { necessitando de } \\
\text { reparação }\end{array}$ \\
\hline Reduzidas & $\begin{array}{c}\text { Algumas alterações nas } \\
\text { atividades portuárias; má } \\
\text { publicidade para o porto a } \\
\text { nível local }\end{array}$ & $\begin{array}{l}\text { Danos interiores } \\
\text { e exteriores } \\
\text { insignificantes }\end{array}$ & $\begin{array}{l}\text { Danos ligeiros que } \\
\text { não implicam a } \\
\text { paragem do } \\
\text { equipamento; } \\
\text { resolução quase } \\
\text { imediata }\end{array}$ & $\begin{array}{l}\text { Ocorrência de } \\
\text { movimentos e quedas } \\
\text { de blocos sem } \\
\text { exposição de filtros; } \\
\text { reparação imediata } \\
\text { desnecessária }\end{array}$ \\
\hline Sérias & $\begin{array}{c}\text { Operações de carga e } \\
\text { descarga condicionadas; } \\
\text { possibilidade de paragem } \\
\text { parcial do porto; má } \\
\text { publicidade generalizada }\end{array}$ & $\begin{array}{l}\text { Danos interiores } \\
\text { moderados }\end{array}$ & $\begin{array}{l}\text { Dano que } \\
\text { implicam } \\
\text { inatividade } \\
\text { temporária do } \\
\text { equipamento para } \\
\text { reparação }\end{array}$ & $\begin{array}{l}\text { Ocorrência de } \\
\text { movimentos e quedas } \\
\text { de blocos com } \\
\text { exposição de filtros; } \\
\text { supraestrutura afetada } \\
\text { mas sem movimentos } \\
\text { significativos }\end{array}$ \\
\hline Muito Sérias & $\begin{array}{c}\text { Impossibilidade da } \\
\text { realização de operações de } \\
\text { carga e descarga durante } \\
\text { vários dias; má publicidade } \\
\text { a nível nacional }\end{array}$ & $\begin{array}{l}\text { Grandes danos } \\
\text { no interior; } \\
\text { estrutura do } \\
\text { edifício afetada }\end{array}$ & $\begin{array}{l}\text { Danos graves; } \\
\text { inatividade } \\
\text { prolongada do } \\
\text { equipamento }\end{array}$ & $\begin{array}{l}\text { Filtros afetados } \\
\text { movimentos } \\
\text { substanciais da } \\
\text { supraestrutura }\end{array}$ \\
\hline Catastróficas & $\begin{array}{l}\text { Restrições muito sérias às } \\
\text { operações de carga e } \\
\text { descarga durante muito } \\
\text { tempo; perda de trocas } \\
\text { comerciais durante muito } \\
\text { tempo; má publicidade } \\
\text { internaci onal }\end{array}$ & $\begin{array}{l}\text { Danos interiores } \\
\text { muito graves; } \\
\text { estrutura do } \\
\text { edifício } \\
\text { seriamente } \\
\text { afetada; colapso } \\
\text { iminente }\end{array}$ & $\begin{array}{l}\text { Perda equipamento } \\
\text { (reparação } \\
\text { impossivel) }\end{array}$ & Colapso da estrutura \\
\hline
\end{tabular}

\section{GALGAMENTOS COSTEIROS NA FAIXA COSTEIRA DA CIDADE DE SANTA CRUZ (1993-2014)}

A cidade de Santa Cruz desenvolve-se entre os 0 metros (linha de costa) e os 50 metros de altitude, no entanto, uma parte significativa do seu núcleo urbano encontra-se até aos 5 metros de altitude o que expõe os elementos urbanos a episódios extremos de agitação marítima, tais como os galgamentos costeiros históricos patentes no quadro 3, sobretudo durante os meses de inverno. A área suscetível a galgamentos costeiros possui uma extensão de 1600 metros e pode atingir os 100 metros para o interior da área urbana, como sucedeu no evento de 01-04-1995 (Реiхото, 2013).

A análise preliminar dos eventos permite concluir que num episódio de agitação marítima de 5 metros de altura, a frente costeira da cidade é inundada. Outra conclusão é a de que os episódios de galgamento costeiro na cidade de Santa Cruz 
podem ser acompanhados por inundação urbana, pois a incapacidade de escoamento na rede pluvial face à penetração marinha, em conjugação com um caudal elevado das ribeiras, reflete-se no escoamento da rede pluvial à superfície (Регхото, 2013). É exemplo desta situação o evento de 0202-2010.

O perigo a galgamento costeiro não é frequente na cidade, contudo, quando se observa apresenta prejuízos de diferentes graus (Регхото, 2013). Uma consequência direta consiste no impedimento da circulação automóvel na Rua da Praia que consequentemente impossibilita o trânsito nas ruas adjacentes, refletindo-se numa diminuição dos clientes dos estabelecimentos comerciais da Rua da Praia e áreas adjacentes, uma vez que, é nesta área que se localiza o estacionamento da cidade. Já nos danos tangíveis é comum registarem-se danos nas estruturas que marginam a costa: a promenade e a destruição de jardins (Регхото, 2013).

No ano de 2013 a frente costeira da cidade registou dois eventos, o primeiro a 3 de março e segundo a 10/11 de dezembro. O primeiro episódio não foi notícia nos meios de comunicação, contudo o registo dos cidadãos demostra que os danos foram sobretudo, estruturais e localizados no Porto de Recreio, com a cedência do pavimento de um setor da estrutura (Figura 2a e b), o qual, com a tempestade de 10 de dezembro acabou por ser destruído na sua totalidade (Figura 2c e d).
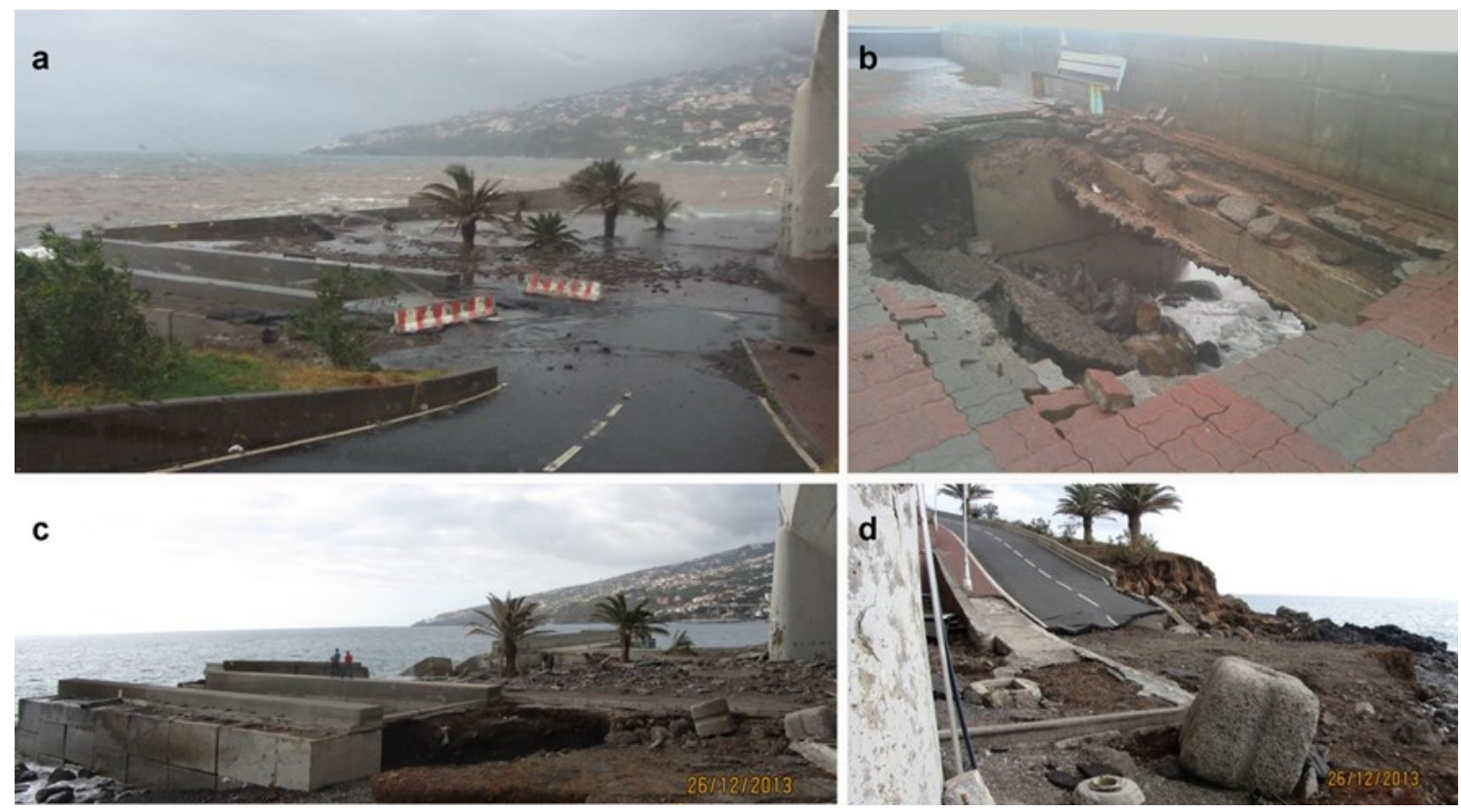

\begin{tabular}{lccccccccccc}
\hline \hline \multicolumn{8}{c}{ Ocorrências de galgamentos costeiros no litoral de Santa Cruz } \\
\hline JAN & FEV & MAR & ABR & MAI JUN JUL AGO & SET & OUT & NOV & DEZ \\
\hline- & 02-02-2010 & $\mathbf{0 3 - 0 3 - 2 0 1 3}$ & $01-04-1995$ & - & - & - & - & - & $30-10-1993$ & - & $\mathbf{1 0 - 1 2 - 2 0 1 3}$ \\
\hline \hline
\end{tabular}

Fig. 2. Destruição do Porto de Recreio pela consequência dos galgamentos costeiros e registo das ocorrências de galgamentos costeiros na cidade de Santa Cruz segundo o mês e datação do mesmo.

Fig. 2. Destruction of the Porto de Recreio caused by overtopping and recording of the overtopping occurrences in the city of Santa Cruz according to the month and date.

\section{O EVENTO DE 10 DE DEZEMBRO DE 2013}

A costa sul da Ilha da Madeira no dia 10-122013 experimentava uma forte agitação marítima desencadeada por uma tempestade extratropical, marcada pelo aumento da intensidade do vento e pela diminuição da pressão atmosférica (Figura 3 c e d), intensificando-se ao longo do dia 10 e durante a madrugada do dia 11. A agitação marítima acompanhou o incremento da intensidade do vento no dia 10 , sobretudo entre das $8 \mathrm{~h}$ às $16 \mathrm{~h}$, hora em que se registou o valor médio máximo de $30 \mathrm{~km} / \mathrm{h}$ (Figura 3c). Em conjugação, observou-se uma diminuição de $50 \mathrm{hPa}$ em 16 horas, o que diminuiu a pressão sobre a massa de água e explica de certa forma a ondulação máxima de 9 metros (Figura 3a). Toda esta conjuntura traduziu-se na formação de um storm surge que motivou um aviso vermelho pelo IPMA. 

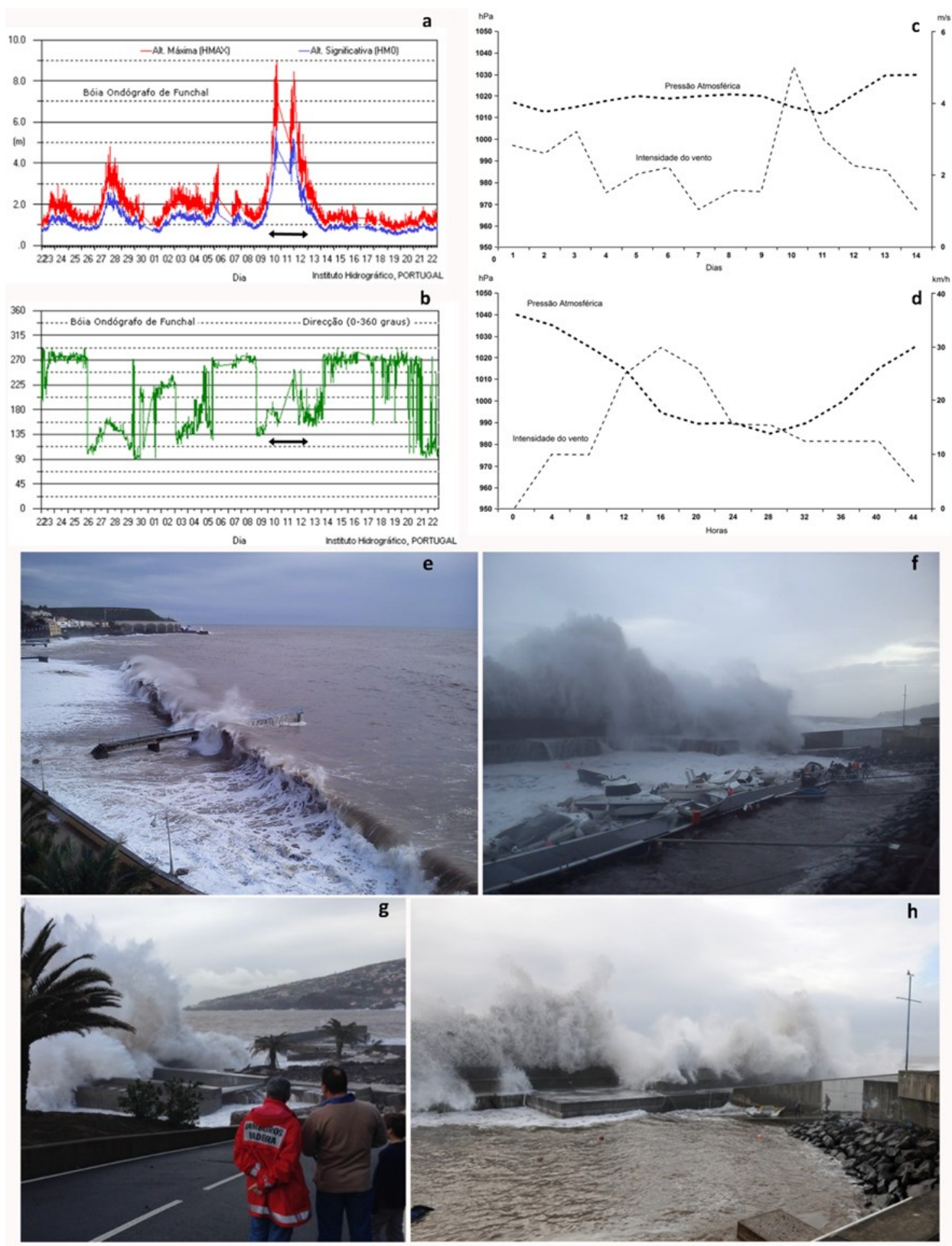

Fig. 3. Dados meteorológicos e oceanográficos de enquadramento da tempestade de 10/11 de dezembro 2013: a - altura da ondulação entre 22 novembro a 22 de dezembro de 2013; b - direção da ondulação entre 22 novembro a 22 de dezembro de 2013; c intensidade do vento, pressão atmosférica na estação meteorológica do Funchal (1 a 14 dezembro de 2013); d - intensidade do vento e pressão atmosférica instantânea na estação meteorológica do Funchal (10 e 11 dezembro de 2013); e - ondulação de SSW f- galgamento do paredão do Porto de Abrigo; h- espraiamento green water no Porto de Abrigo; g - espraiamento green water no Porto de Recreio.

Fig. 3. Meteorological and oceanographic data of the storm on 10/11 December 2013: a - swell height from 22 November to 22 December 2013; b - swell direction from 22 November to 22 December 2013; c - wind intensity, atmospheric pressure at Funchal weather station ( 1 to 14 December 2013); d - wind intensity and instantaneous atmospheric pressure at Funchal weather station (10 and 11 December 2013); e SSW swell; f- overtopping of the Abrigo Harbour; h- green water spreading at Abrigo Harbour; g-green water spreading at Recreio Harbour.

No que refere à escala local os ventos registados na Estação de Santa Catarina, concelho de Santa Cruz, circulavam com uma velocidade média de $24 \mathrm{~km} / \mathrm{h}$ e com uma predominância de SW o que se aproximou da direção da ondulação que oscilou no dia 10 entre SE e o SSW durante o dia, atingindo no final do dia uma direção de SSE, marcando-se às $12 \mathrm{~h}$ uma mudança de direção (Figura 3b). A ondulação caracterizou-se por uma altura máxima de 9 metros intercalada com ondas de 5 metros que quebraram muito próximo da linha de costa (Figura 3e).

As ondas mantiveram-se com altura elevada até o dia 13 , o que demonstra que a tempestade durou 3 dias, sendo o primeiro dia mais intenso (Figura 3a). Assim, registou-se mais uma exceção aos valores normais da estação do Funchal, confirmando-se que quanto maior é a duração da tem- 
pestade maior é altura da ondulação. A direção da ondulação manteve-se no quadrante sul nos dias seguintes. Note-se, no entanto, que os valores de dia 11 registam lacunas, passando de SSE para SW no dia 12 de dezembro. Deste modo, verificase que a ocorrência da tempestade não possuiu uma direção dominante, mas sim, uma variação de $45^{\circ}$ no dia 10 e de $90^{\circ}$ para o dia 12 , regressando a oeste, i.e., à direção predominante, no dia 14 de dezembro.

Os dados registados nas estações meteorológicas e boias ondógrafos permitem inferir que o galgamento costeiro adveio de uma tempestade extratropical de intensidade moderada, uma vez que, ocorrência ocorreu num contexto de diminuição da pressão atmosférica, onde os ventos locais possuíam a direção de SW. A ondulação registou valores de altura máxima entre os 8 a 9 metros e com períodos máximos de 8 a 15 segundos, situação correspondente à tempestade extratropical classificada por DemIRBILEK \& VICENT (2002).

A interação entre a onda-estrutura resultou num espraiamento elevado da ondulação que transpôs o coroamento das estruturas ocorrendo sucessivos galgamentos do tipo green water (Figura 3f, g e h). O mesmo processo foi registado nas praias onde o espraiamento influenciado também pelo vento, e a deriva costeira motivada pela forte ondulação transportou material de variada dimensão (blocos, calhaus, troncos de árvore, fragmentos das embarcações destruídas e das obras costeiras, assim como muito lixo urbano) e depositou-o ao longo da promenade e nas estrutu- ras galgadas. Segundo os dados apurados a maioria do material transportado e depositado na frente costeira, principalmente os troncos e restos de árvores, serão provenientes do episódio de precipitação intensa de 29 de novembro de 2013, em que os caudais das ribeiras transportaram abundante material resultante dos incêndios do verão.

$\mathrm{O}$ galgamento das estruturas portuárias efetuou-se segundo dois tipos de fluxo relacionados com a altura da onda e o modo de transposição da estrutura (Figura 4). O primeiro, designado por fluxo I, sucedeu-se sempre com as ondas com altura máxima, transponde a totalidade do muro até ao interior do porto, atingindo diretamente a plataforma interior de amarração das embarcações. Já o segundo fluxo, advindo de ondas de menor altura galgou a estrutura em forma de escada, perdendo energia ao longo do percurso até o interior do porto. A combinação destes fluxos em conjunção com a entrada lateral da ondulação no Porto de Abrigo originou um movimento de oscilação no interior do porto semiaberto, formando as seichas responsáveis pela destruição das embarcações e da plataforma (Figura 4). Já o galgamento no Porto de Recreio afetou a estrutura através de (Figura 4): i) galgamento do muro de proteção; ii) um fluxo que circulava pelo vazio deixado na estrutura pela cedência do pavimento advindo do evento de 03 03-2013; iii) espraiamento oriundo pela rampa de acesso das embarcações ao mar.

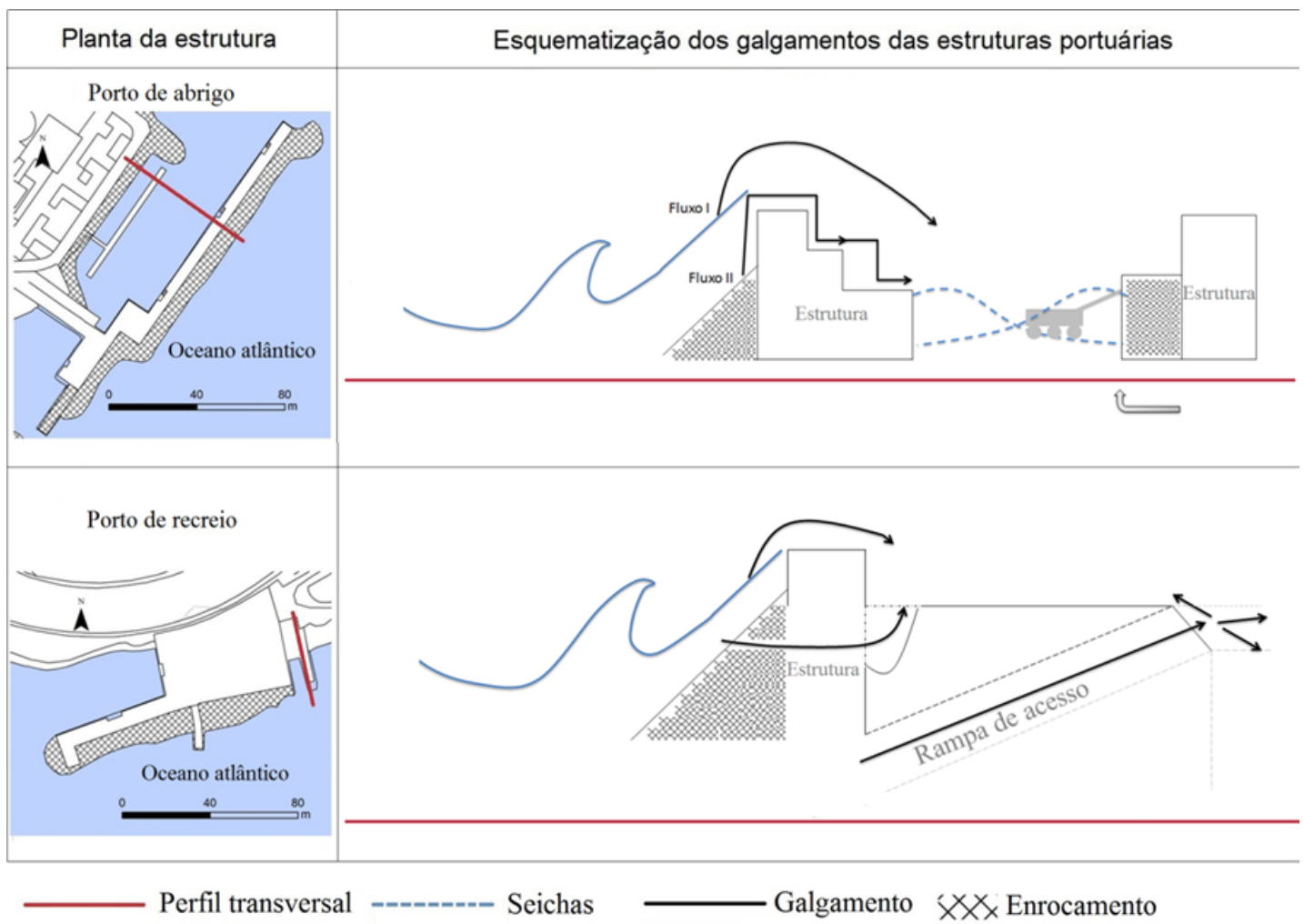

Fig. 4. Hipótese sobre a circulação do espraiamento da agitação marítima de 10/11-12-2013 nas estruturas portuárias. Fig. 4. Hypothesis about the spreading circulation of the storm surge on 10/11-12-2013 in the harbour structures. 
As consequências da tempestade marítima ocorreram quando a pressão atmosférica atingiu os $1010 \mathrm{hPa}$ (entre as $16 \mathrm{~h}$ e as $18 \mathrm{~h}$ do dia 10 ) e as rajadas de ventos rondavam os $30 \mathrm{~km} / \mathrm{h}$ (Figura 5). Desse modo, interditaram a promenade aos cidadãos (a área de passeio e lazer), uma vez que o espraiamento atingia o equipamento. Com a intensificação da propagação das ondas registou-se: i) afundamento de embarcações; ii) corte de vias rodoviárias; iii) inundação num estabelecimento comercial. Em resposta aos danos, na madrugada do dia 11, a autarquia iniciou as ações de minimização das consequências com a remoção do material que impedia o desaguar da Ribeira de Santa Cruz. Na manhã do mesmo dia contabilizaram-se os estragos e começaram as operações de limpeza, bem como, a divulgação que o parque de estacionamento do Porto de Recreio e área adjacente estavam totalmente ou parcialmente destruídos.

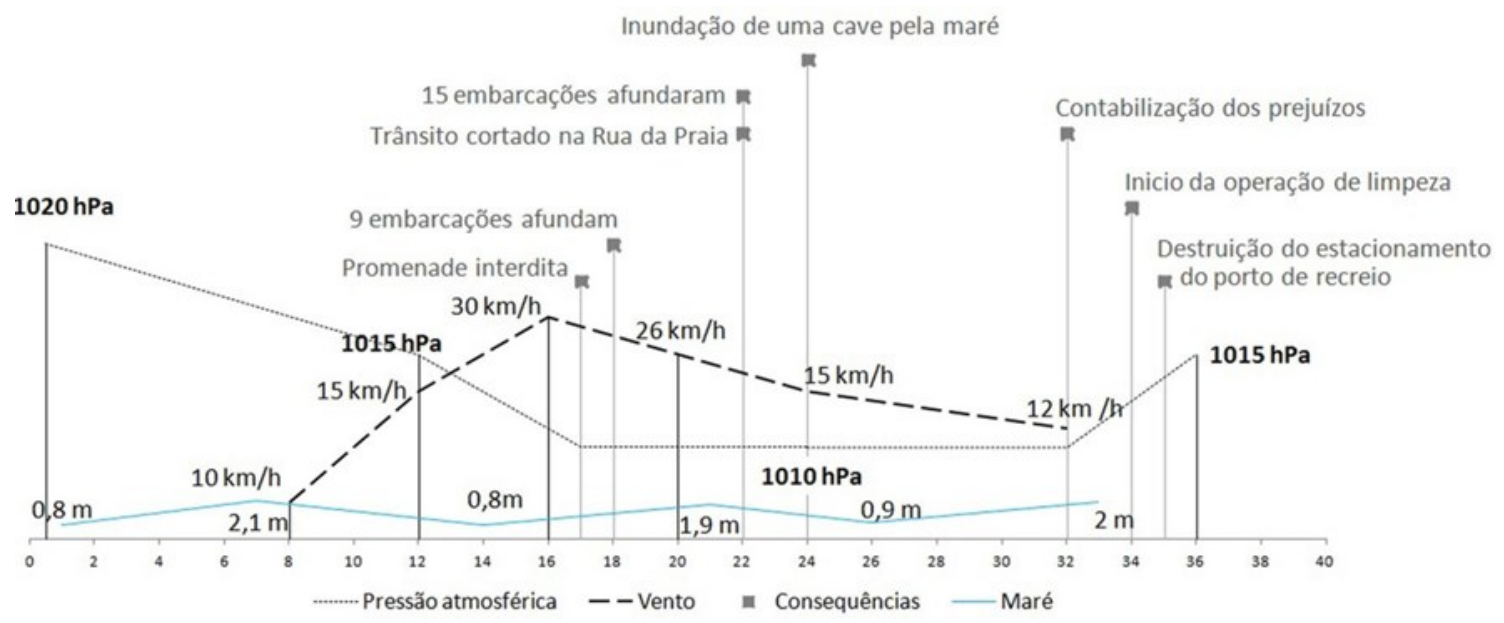

Fig. 5. Sucessão dos acontecimentos, desde as $00.00 \mathrm{~h}$ do dia 10-12-2013 às 13:00h do dia 11-12-2013 do galgamento costeiro na cidade de Santa Cruz.

Fig. 5. Sequence of events, from $00.00 \mathrm{hrs}$ on 10-12-2013 to $13.00 \mathrm{hrs}$ on 11-12-2013 of overtopping in the Santa Cruz city.

\subsection{Consequências na faixa costeira de Santa Cruz resultantes do galgamento costeiro de 10/11 de dezembro de 2013}

A energia da agitação marítima e sucessiva transposição das estruturas e equipamentos costeiros repercutiu-se no território através das modificações na faixa costeira, em prejuízos na propriedade pública e em bens públicos e privados.

No que se refere à nova configuração da linha de costa ocorreram dois processos, a erosão que ocorreu na praia frente unidade hoteleira e na área do Porto de Recreio, e uma acentuada acreção que se deu nas praias localizadas a oriente das fozes dos principais cursos de água (Figura 6a e g), resultando num aumento da largura e extensão destas praias (Figura 6h). Cremos que a acreção foi motivada pela deriva litoral local que se estabeleceu durante a tempestade.

Mediante a observação direta detetaramse rapidamente as consequências insignificantes na faixa costeira considerada, que consistiu na deposição de material (Figura $6 \mathrm{f}$ e i), o que se verificou em quase toda a extensão da área afetada. O material depositado foi sobretudo composto por troncos de árvores, lixo urbano e calhaus e blocos, bem como, os restos das embarcações destruídas (Figura 6f). O efeito destrutivo da energia das ondas foi amplificado pelo arremesso de sedimentos grosseiros dado que as praias são es- sencialmente constituídas de material grosseiro (seixos e calhaus), o que danificou parcialmente as estruturas que marginavam o litoral. São exemplo destas consequências, os blocos que cobriam os muros e o levantamento da calçada dos acessos pedonais. A estes danos atribuiu-se o grau de reduzido. Esta classificação baseou-se na observação de fendas no Porto de Abrigo (Figura 6b e c), enquadrando-se na tipificação de "ocorrência de movimentos e quedas de blocos sem exposição de filtros e reparação imediata desnecessária”; já a promenade registou "danos ligeiros que não implicam a paragem do equipamento e a sua resolução é quase imediata" RocHA et al. (2012). $\mathrm{O}$ grau de consequências sério, verificou-se nas piscinas municipais (Figura 6i) e na promenade desde a Ribeira do Moreno até ao Porto de Recreio (Figura 51). Tanto nas piscinas municipais como na promenade o dano implicou a inatividade temporária do equipamento para reparação.

O quarto nível de consequências, grau muito sério, registou-se em elementos do Porto de Recreio (Figura 6m e n), onde os danos são considerados graves, implicando uma inatividade prolongada do equipamento, bem como, nalguns segmentos da estrutura de proteção observou que existiam "filtros afetados e movimentos substanciais da supraestrutura". No edifício de apoio (balneários), o interior foi afetado, bem como, a própria estrutura (Figura 5n). 
As consequências da tempestade marítima ocorreram quando a pressão atmosférica atingiu os $1010 \mathrm{hPa}$ (entre as $16 \mathrm{~h}$ e as $18 \mathrm{~h}$ do dia 10 ) e as rajadas de ventos rondavam os $30 \mathrm{~km} / \mathrm{h}$ (Figura 5). Desse modo, interditaram a promenade aos cidadãos (a área de passeio e lazer), uma vez que $\mathrm{o}$ espraiamento atingia o equipamento. Com a intensificação da propagação das ondas registouse: i) afundamento de embarcações; ii) corte de vias rodoviárias; iii) inundação num estabeleci- mento comercial. Em resposta aos danos, na madrugada do dia 11, a autarquia iniciou as ações de minimização das consequências com a remoção do material que impedia o desaguar da Ribeira de Santa Cruz. Na manhã do mesmo dia contabilizaram-se os estragos e começaram as operações de limpeza, bem como, a divulgação que o parque de estacionamento do Porto de Recreio e área adjacente estavam totalmente ou parcialmente destruídos.

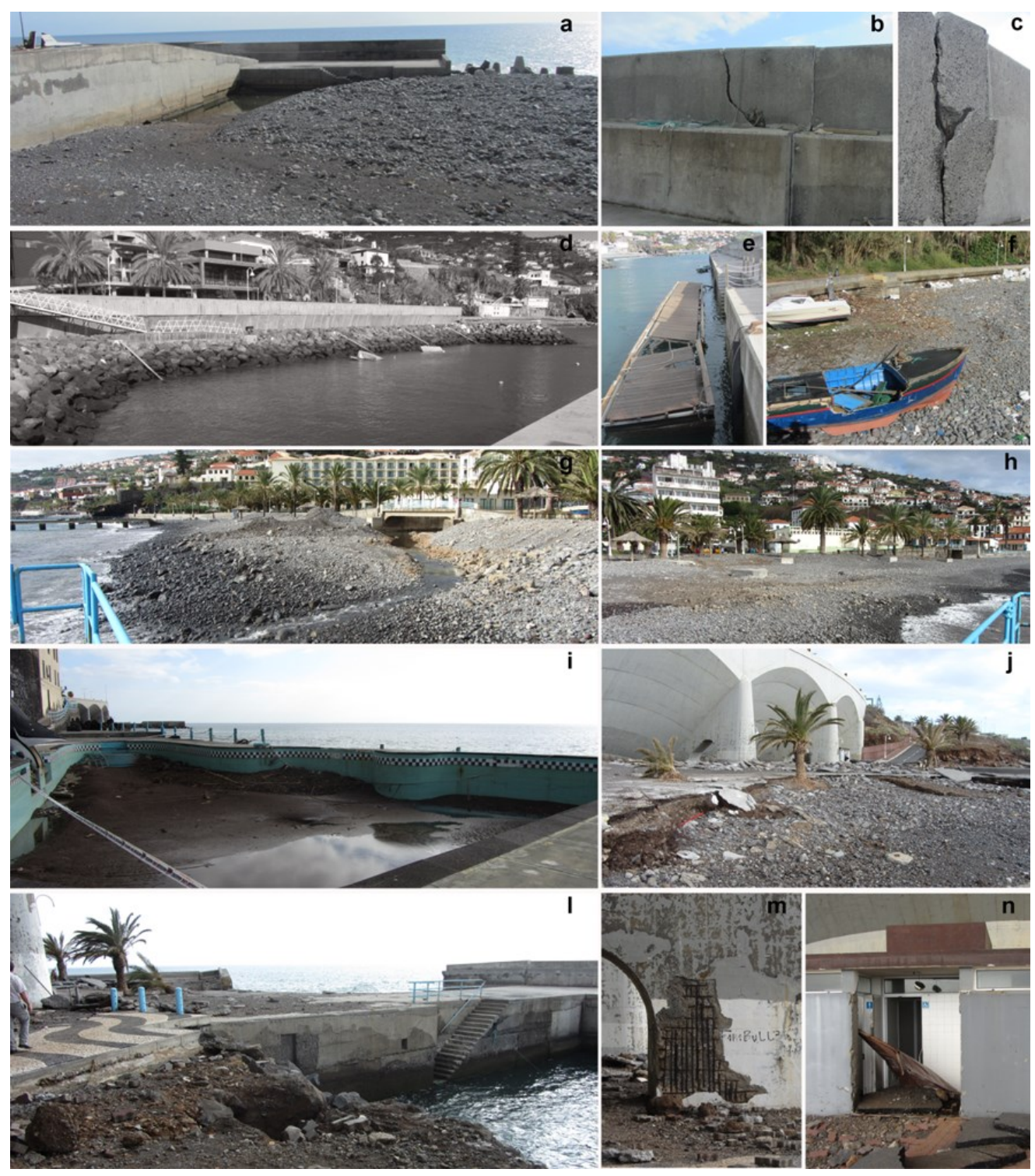

Fig. 6. Consequências do galgamento costeiro de 10/11-12-2013 registados na frente costeira da cidade de Santa Cruz no dia 2612-2013: a - acreção sedimentar na praia; b, c - fendas na infraestrutura do porto; d- destruição das plataformas flutuantes; e ausência dos elementos do porto devido a sua destruição; $\mathrm{f}$ - depósito de material e barcos parcialmente destruídos; $\mathrm{g}$ - mudança da foz; h- a acreção sedimentar da praia e aumento a largura da praia; i- destruição de elementos, como varandas e da própria infraestrutura da piscina municipal; j- destruição parcial do parque de estacionamento do Porto de Recreio; i - levantamento da calçada dos acessos; $\mathrm{m}$ - danificação dos pilares de suporte da via rápida (VR1); n- destruição parcial dos balneares.

Fig. 6. Consequences of the overtopping on 10/11-12-2013 recorded on the coastal front of Santa Cruz city on 26-12-2013: a - sediment accretion in the beach; $b, c$ - cracks in the harbour infrastructure; $d$ - destruction of the floating platform; $e$ - elements absence of the harbour due its destruction; f - material and boats deposit partially destroyed; $\mathrm{g}$ - estuary changes; $\mathrm{h}$ - sediment accretion of the beach and increase the width of the beach; $i$ - destruction of elements, such as balconies and the municipal swimming pool infrastructure itself; jpartial destruction harbour's car park; $i$ - lifting of the accesses' pavement; m- damage of the support pillars of the fast way (VR1); npartial destruction of the bathing spots. 
As consequências catastróficas, registaramse no Porto de Abrigo com a perda da plataforma de amarração e o afundamento de 15 embarcações, e no Porto de Recreio onde se deu o colapso da estrutura que suportava a área de lazer e o parque de estacionamento.

Para além dos danos estruturais, deve-se considerar a disfunção portuária, que no caso do porto abrigo é classificada como catastrófica, uma vez que, não é possível atividade naquela área devido à ausência das plataformas.

Em síntese, a estrutura com maiores danos foi o Porto de Recreio (Figura 6j) que ficou totalmente destruído apenas restando o pontão. Todos os elementos adjacentes a esta estrutura, como candeeiros públicos, canalização e balneários ficaram destruídos, sendo a área atualmente depósito do material. O material que foi projetado pela energia das ondas acabou por danificar suportes da estrutura da VR1 (via-rápida), nada menos que o principal eixo de ligação das cidades da costa sul.

\section{DISCUSSÃO E CONCLUSÕES}

A ocorrência dos galgamentos costeiros na cidade de Santa Cruz, embora não sendo frequen- te, acarreta prejuízos que conduzem a custos diretos (reconstrução, recuperação) e indiretos (disfunção de equipamentos) à cidade e aos seus habitantes.

O galgamento de 10/11-12-2013 permite concluir que o episódio de forte agitação marítima de quadrante Sul advindo de uma tempestade extratropical caraterizada por um rápido abaixamento da pressão atmosférica e ventos de $30 \mathrm{~km} / \mathrm{h}$ causou danos sérios e catastróficos na frente costeira da cidade Santa Cruz. Assim, estima-se que os elementos urbanos localizados aproximadamente até aos 5 metros de altitude e até aos 100 metros no interior da cidade estão expostos, tanto diretamente ao espraiamento e sucessivo material transportado, como indiretamente aos efeitos da inundação por galgamento. É exemplo a interditação do trânsito na marginal por precaução.

Para além da exposição às massas de água, a frente costeira da cidade está sujeita a processos de erosão e acreção (Figura 7). Note-se que os processos de acreç̃o sedimentar ocorreram não só pela direção das ondas (SE a SSW), mas também, pelo facto das ribeiras alimentarem a costa com sedimentos, em simultâneo, o que se traduziu numa acreção no setor oriental das ribeiras.

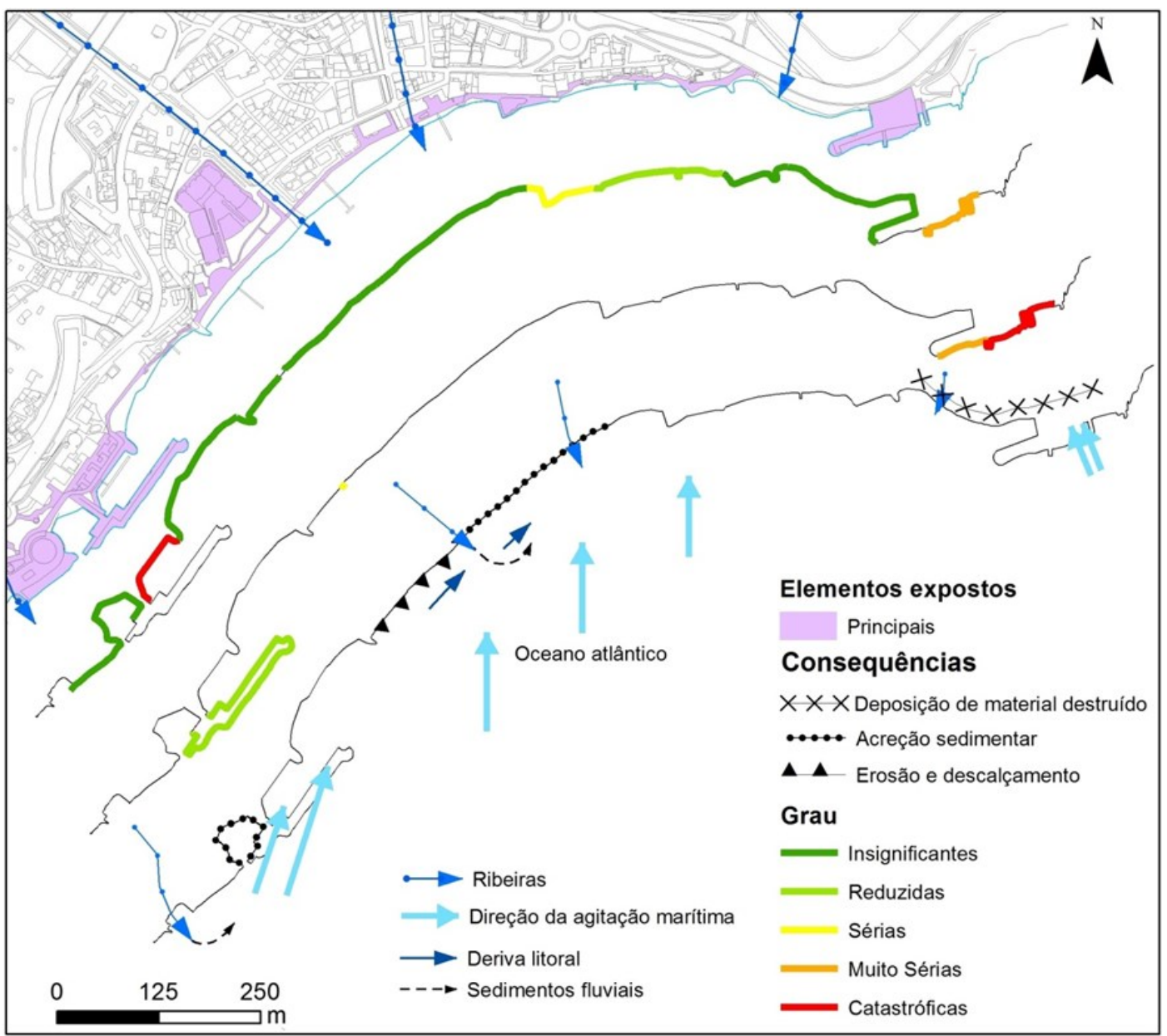

Fig. 7. Síntese das consequências segundo o grau e tipo do galgamento costeiro de 10/11-12-2013 e dos processos ocorridos. Fig. 7. Summary of the consequences according to the degree and overtopping type of 10/11-12-2013 and the processes that occurred. 
As áreas em que os danos foram sérios a catastróficos encontram-se nos extremos da faixa costeira, registando-se na área intermédia os danos reduzidos a insignificantes. Os prejuízos no Porto de Recreio não advieram apenas da ocorrência do galgamento em análise, mas sim, da conjugação de dois episódios de forte agitação marítima.

$\mathrm{Na}$ atualidade, os principais elementos expostos ao perigo de galgamento são: i) o Porto de Abrigo, que apesar de não necessitar de reparação imediata pode ver os danos acentuados em episódios futuros; ii) as piscinas municipais, uma vez que, é um equipamento sazonal utilizado por um grande número de habitantes locais e pelos turistas. No que se refere à extensão, é a promenade o elemento urbano mais afetado, pois possuiu 1600 metros expostos aos galgamentos costeiros.

Conclui-se assim que é essencialmente a propriedade pública que está exposta, i.e., as piscinas municipais, as estruturas portuárias e a promenade.

Apesar, da gravidade dos danos, o evento de 10 de dezembro não corresponde aos valores máximos de ondulação registados pela boia ondógrafo no período de 1993 a 2013, o que demonstra que em episódios com ondas superiores a 8 metros, podem ocorrer graves danos nos elementos costeiros. Por tudo isto, a quantificação dos eventos de agitação marítima e sucessivo registo de consequências deverão de ser a base para uma política municipal de ordenamento do território costeiro, de modo a prevenir em episódios futuros consequência de grau muito sério a catastrófico.

\section{AGRADECIMENTOS}

À Câmara Municipal de Santa Cruz agradecemos a cedência de cartografia vetorial, de ortofotomapas e o estágio profissional que facultou à autora. À população da cidade de Santa Cruz pelo relato das ocorrências e esclarecimento das consequências. Ao Sr. Roberto Abreu e Sr. Hélder Santos pela cedência das fotos relativas aos galgamentos costeiros de 3-03-2013 e de 10/11-12-2013.

\section{BIBLIOGRAFIA}

ANPC. Riscos Costeiros - Estratégias De Prevenção, Mitigação E Protecão, No Âmbito Do Planeamento De Emergência E Do Ordenamento Do Território. Cadernos Técnicos PROCIV 15, 2010.

BRITo, S. F. Estudo Do Galgamento Em Estruturas Marítimas. Dissertação de Mestrado em Engenharia Civil, Instituto Superior Técnico (IST), Lisboa, 2007.

Campuzano, F. J; Nunes, S., Malhadas M.; Nunes, D, JARDIM, M.; Neves, R. Modelação Da Hidrodinâmica Da Orla Sul Da Ilha Da Madeira. 6as Jornadas Portuguesas de Engenharia Costeira e Portuária, Funchal (8 e 9 de outubro), 2009.

Campuzano, F. J; Nunes, S.; Malhadas, M.; Nunes, D.; NEvES, R. Efeito das Descargas De Águas Residuais e Emissários Submarinos na Produção Primaria Da Costa Sul Da Ilha Da Madeira., 2004.

Demirbilek, Z.; Vincent, L. Chapter Ii-1: Water Wave Mechanics. In Coastal Engineering Manual -
Engineer Manual 1110-2-1100, edited by U.S Army Corps of Engineers. Washington, DC., 2002.

Dwyer, A.; Zoppou, C; Nielsen, O.; Day, S.; Roberts, S. Quantifying Social Vulnerability: A Methodology for Identifying Those at Risk to Natural Hazards Geoscience Australia Canberra, Australia, 2004.

Esteves, R.; Pinto, J. P. Análise Climatológica Da Agitação Marítima Na Costa Sul Da Madeira. 2007.

Fernandes, M. J. P. Riscos No Concelho Da Ribeira Brava Movimentos De Vertente Cheias Rápidas e Inundações. Dissertação da Faculdade de Letras da Universidade de Coimbra, 2009

Fitzgerald, D. M; Van H.; Montello, M. T.. Shoreline Processes and Damage Resulting from the Halloween Eve Storm of 1991 Along the North and South Shores of Massachusetts Bay, USA. Journal of Coastal Research, 1994.

Haslett, S.K.; Bryant, E. A. meteorological tsunamis in southern britain: an historical review. Geographical Review, 99, 2, 146-163, 2009.

HsiaO, S., LIN, T. - Tsunami-like solitary waves impinging and overtopping an impermeable seawall: Experiment and RANS modeling. Coastal Engineering, 57: $1-18.2010$

Instituto Hidrográfico - Tabela de marés para o porto do Funchal, $4^{\circ}$ trimestre de 2013.

IPPC. Climate Change 2013, The Physical Science Basis Cambridge University Press, 1552 p., 2013.

Lynett, P. J.; Borrero, J. C.; LiU, P.L.-F.; Synolakis, C. E. Field Survey and Numerical Simulations: A Review of the 1998 Papua New Guinea Tsunami. Pure and Applied Geophysics, 160: 2119-2146. 2003.

Kron, W.. Coasts: The High-Risk Areas of the World Natural hazards 66, no. 3, 2013.

Neves, D. M.F. Turismo E Riscos Na Ilha Da Madeira Avaliação, Percepção, Estratégias De Planeamento E Prevenção. Dissertação da Faculdade de Letras da Universidade de Coimbra, 2010

PAtrício, T. M. D. S.. Modelação numérica do galgamento de quebra-mares de talude, 2012.

Peixoto, A. Inundações Urbanas, Cheias Rápidas E Galgamentos Costeiros Na Cidade De Santa Cruz, Ilha Da Madeira: Áreas Afetadas, Frequência E Avaliação Da Vulnerabilidade Funcional. Faculdade de Letras da Universidade do Porto, 2013

Pullen, T.; Allsop, N.; Bruce, T.; Kortenhaus, A.; Sch, H.; VAN DER MEER, J. Wave overtopping of sea defences and related structures: assessment manual, 2007.

Rocha, T., Teresa-reis, M; Fortes, C.; TaVeira-Pinto, F.; Santos, J.A.; Neves, D.; Portela, L. Influência Da Variação Do Nível De Maré Na Avaliação Do Risco De Galgamento Na Baía Da Praia Da Vitória, Terceira, Acores. In $7^{a}$ Jornadas de Hidráulica, Recursos Hidricos e Ambiente. FEUP, 2012.

Rodrigues, E. J. C.. Galgamento De Estruturas Marítimas: Comparação De Ferramentas De Cálculo. Instituto Politécnico de Setúbal, 2011.

Rusu, E.; Soares, C G. Wave Energy Pattern around the Madeira Islands. Energy, 45, no. 1: 771-785, 2012.

Rusu, E.; Pilar, P.; SoARes C. G.. Evaluation of the Wave Conditions in Madeira Archipelago with Spectral Models. Ocean Engineering, 35, no. 13 (2008): $1357-1371$ 
SChefFner, N. W. Chapter 5: Water Levels and Long Waves. In Coastal Engineering Manual -Engineer Manual 1110-2-1100, edited by U.S. Army Corps of Engineers, Vol. II. Washington, DC., 2002.

Smith, J. M. Chapter II-4: Surf Zone Hydrodynamics. In Coastal Engineering Manual-Engineer Manual 1110-2-1100, edited by U.S. Army Corps of Engineers. Washington, DC., 2002.

Silva, D. M. F.; Fortes, C. J.; Teresa-reis, M.; Carmo, J. S.;Simões, A.; Rodrigues, C.. Avaliação Do Galgamento De Estruturas Portuárias: Porto De Ponta Delgada. Recursos Hidricos, 33, no. 2 , 2012.

Storch, H. V.. Storm Surges: Phenomena, Forecasting and Scenarios of Change." Procedia IUTA, 10, 2014.

Thompson, E. F. Chapter 8: Hydrodynamic Analysis and Design Conditions. In Coastal Engineering Manual-Engineer Manual 1110-2-1100, edited by U.S. Army Corps of Engineers, Vol. II. Washington, DC., 2002.

Torres, C.; Andrade, C. Processo De Decisão De Análise Espacial Na Selecção De Áreas Óptimas Para a Aquacultura Marinha: O Exemplo Da Ilha Da Madeira. Revista da Gestão Costeira Integrada, 10, no. 3 (2010): 321-330.

UsACE - U.S. Army Corps of Engineering. Engineering and Design: Coastal Engineering (Engineer Manual 1110-2-1810). Washington, DC 1995.

Vídeos

http://www.dnoticias.pt/multimedia/video/420813agitacao-maritima-no-cais-do-aeroporto-da-madeira, acedido em 26 de dezembro de 2013.

https://www.youtube.com/watch? $\mathrm{v}=\mathrm{x} 1 \mathrm{seGHqLIVw}$, acedido em 03 de março de 2014.

Sites

INSTITUTO HIDROGRÁFICO - http://www.hidrografico.pt boias-ondografo.php, acedido em 22 de dezembro de 2013.

Instituto Português do Mar E DA AtMosfera http:// www.ipma.pt/pt/otempo/obs.superficie.grafica/, acedido em 04 de janeiro de 2014

NOAA - http://www.stormsurge.noaa.gov/, acedido em 10 de março de 2014.

InSTITUTO NACIONAL DE EstatístiCA-http://www.ine.pt/ xportal/xmain?

xpid=INE\&xpgid $=$ ine indicadores\&indOcorrCod $=00000$ $09 \&$ contexto $=$ bd\&selTab $=$ tab 2 , acedido em 21 de março de 2014 .

CIIMAR-MADEIRA - http://wakes.uma.pt/pt/ research.php, acedido em 20 de abril de 2014. 